Artigo Original

OriginAL ArTicLE

\title{
Pesquisa de Anticorpos Antinucleossoma em Lúpus Eritematoso Sistêmico
}

\section{Detection of Antinucleosome Antibodies in Systemic Lupus Erythematosus}

\author{
Isabella Lima ${ }^{(1)}$, Lúcio Barbosa ${ }^{(2)}$, Mabel Lopes $^{(2)}$, Eliana Reis ${ }^{(2)}$, Mitermayer Reis ${ }^{(2)}$, Karina Colossi ${ }^{(3)}$, \\ Maurício Abreu $^{(3)}$, Clarissa Ferreira ${ }^{(3)}$, Mittermayer Santiago ${ }^{(4)}$
}

\section{RESUMO}

Objetivos: determinar a freqüência dos anticorpos antinucleossoma (AN) em lúpus eritematoso sistêmico (LES) e avaliar a associação desses anticorpos com a atividade de doença. Métodos: estudo de corte transversal em que foram estudados pacientes com diagnóstico de LES baseado nos critérios do Colégio Americano de Reumatologia. Utilizou-se o SLEDAI como instrumento de avaliação de atividade de doença. A pesquisa de anticorpos AN foi realizada pela técnica de ELISA (INOVA Diagnostics Inc). Pacientes com diagnóstico de miosite e esclerose sistêmica (ES) foram também estudados para avaliação da performance do teste. Resultados: foram estudados 82 pacientes com LES, sendo 81 do sexo feminino, com idade média de $35 \pm 11,7$ anos. Anticorpos AN foram detectados em 48 pacientes com LES $(58,5 \%)$, em três pacientes com miosite $(21,4 \%)$ e em dois pacientes com ES (14,2\%), o que determinou sensibilidade e especificidade de $58,5 \%$ e $82,14 \%$, respectivamente. Considerando-se um ponto de corte em $40 \mathrm{U}$, os anticorpos AN foram detectados em 44 pacientes com LES $(53,65 \%)$, em dois pacientes com miosite (13,33\%) e em um paciente com ES $(6,66 \%)$, o que determinou sensibilidade e especificidade de $53,65 \%$ e $90 \%$, respectivamente. Não se observou correlação dos títulos dos anticorpos AN e a atividade de doença (SLEDAI), embora tenha sido observada correlação entre anti-DNA e escore de SLEDAI nessa mesma população $(r=0,42 ; \mathrm{p}<0,005)$. Conclusões: No presente estudo, observaram-se moderada sensibilidade e alta especificidade dos anticorpos AN para o diagnóstico de LES. No entanto, não se verificou associação desses anticorpos com os parâmetros de atividade da doença, sugerindo que a pesquisa de tais anticorpos seria de valor limitado na prática reumatológica.

Palavras-chave: lúpus eritematoso sistêmico, antinucleossoma, SLEDAI.

\section{ABSTRACT}

Objective: to determine the frequency of antinucleosome (AN) antibodies in systemic lupus erythematosus (SLE) and their association with disease activity. Methods: cross-sectional study to evaluate patients with diagnosis of SLE based on the American College of Rheumatology criteria. SLEDAI score was used as a disease activity index. AN antibodies were tested by ELISA (INOVA Diagnostics Inc). Systemic sclerosis $\left(S S_{c}\right)$ and myositis patients were also studied to determine the diagnostic performance of the ELISA system. Results: a total of 82 SLE patients, 81 female, mean age $35 \pm 11.7$ years were included in the study. AN antibodies were positive in 48 SLE samples (58.5\%), three with myositis (21.4\%) and two with SSc (14.2\%), determining a sensitivity and specificity of $A N$ antibodies for the diagnosis of SLE of $58.5 \%$ and $82.14 \%$, respectively. Utilizing a cut off of $40 \mathrm{U}$, test was positive in 45 SLE samples (53.65\%), two with myositis (13.33\%) and one with SSc (6.66\%), determining a sensitivity and specificity of $A N$ antibodies for the diagnosis of SLE of $53.65 \%$ and $90 \%$, respectively. There were no correlation between AN antibodies and SLEDAI scores. On the other hand, it was observed a positive correlation between anti-DNA antibodies and disease activity $(r=0.42 ; p<0.005)$. Conclusions: in the present study it was demonstrated a high specificity and moderate sensitivity of $A N$ antibodies for the diagnosis of SLE. However, the lack of association with disease activity suggests that it has limited value in rheumatologic practice.

Keywords: systemic lupus erythematosus, antinucleosome, SLEDAI.

Recebido em 16/10/06. Aprovado, após revisão, em 15/05/07.

1. Reumatologista no Serviço de Reumatologia do Hospital Santa Izabel, Salvador, Bahia

2. Laboratório de Biologia Molecular Fundação Gonçalo Muniz - FIOCRUZ.

3. Internos da Escola Bahiana de Medicina e Saúde Pública (EBMSP).

4. Chefe do Serviço de Reumatologia do Hospital Santa Izabel e professor adjunto da EBMSP, Salvador, Bahia.

Endereço para correspondência: Mittermayer B. Santiago, Praça Conselheiro Almeida Couto, 500, CEP 40000-000, Nazaré, Salvador, BA, Brasil, telefax: (71) 3326-5276, e-mail:mitter@svn.com.br. 


\section{INTRODUÇÃO}

O lúpus eritematoso sistêmico (LES) é uma doença auto-imune, de etiologia não completamente esclarecida, que concorre com significativa morbi-mortalidade para os pacientes acometidos, em sua maioria mulheres jovens. Sua classificação, proposta pelo Colégio Americano de Reumatologia (ACR), baseia-se na presença de quatro dos 11 critérios em qualquer fase de evolução da doença ${ }^{(1)}$. No entanto, freqüentemente há dificuldades em se estabelecer o diagnóstico em vista de sua apresentação clínica polimórfica, bem como a inespecificidade dos exames diagnósticos.

Vários estudos em andamento têm buscado exames mais sensíveis e específicos para o diagnóstico do LES, e estudos de fisiopatogenia têm apontado o nucleossoma como um auto-antígeno que, a partir de sua exposição pela apoptose, torna-se capaz de induzir a produção de anticorpos, mediadores das lesões teciduais no $\operatorname{LES}^{(2-5)}$. À luz desse conhecimento, tem-se buscado o significado da pesquisa de anticorpos antinucleossoma (AN) como teste diagnóstico para o LES. O objetivo do presente estudo foi determinar a relevância dos anticorpos antinucleossoma (AN) no LES e avaliar a associação desses anticorpos com a atividade da doença.

\section{MATERIAL E MÉTODOS}

Foram estudados pacientes com diagnóstico de LES baseado nos critérios da $\mathrm{ACR}^{(1)} \mathrm{em}$ acompanhamento no Serviço de Reumatologia do Hospital Santa Izabel, Salvador, Bahia. Também foram estudados pacientes com diagnóstico de esclerose sistêmica $(\mathrm{ES})^{(6)}$ e miosite ${ }^{(7,8)}$ segundo os critérios previamente publicados, acompanhados no mesmo serviço. Todos os pacientes assinaram o Termo de Consentimento Livre e Esclarecido antes de entrarem no estudo.

Os pacientes portadores de LES foram avaliados quanto à atividade da doença utilizando-se como instrumento o Systemic Lupus Erythematosus Disease Activity Index $(\text { SLEDAI })^{(9)}$. A pesquisa de anticorpos anti-DNA nativo foi realizada por imunofluorescência indireta, utilizando-se a Crithidia luciliae como substrato ${ }^{(10)}$. A pesquisa de anticorpos antinucleossoma utilizou o método de ELISA por meio de um kit adquirido comercialmente (INOVA Diagnostics Inc., San Diego, CA). Tal método tem como substrato a cromatina purificada de timo bovino, e foi utilizado como ponto de corte o valor de $20 \mathrm{U}$ para expressar os resultados como positivos, como sugerido pelo fabricante. A análise estatística foi realizada utilizando-se o programa Statistical
Package for the Social Sciences (SPSS Chicago - IL, versão 9.0, 1998). As variáveis nominais foram descritas sob a forma de freqüências, e as variáveis intervalares, sob a forma de média \pm desvio-padrão. Utilizou-se o teste $t$ de Student para comparar médias; a associação entre variáveis qualitativas foi estudada pelo teste de qui-quadrado ou exato de Fisher quando indicado, e a correlação entre variáveis contínuas foi estudada pelo teste de Pearson. Para todos os testes estatísticos, considerou-se significância o valor de $\mathrm{p}<0,05$. Calcularam-se sensibilidade, especificidade e valor preditivo positivo dos AN para o diagnóstico de LES utilizando-se um programa específico: (http://faculty. vassar.edu/lowry/VassarStats.html).

\section{RESULTADOS}

Foram estudados 112 pacientes, sendo 82 com diagnóstico de LES e 30 controles, que envolviam 15 pacientes com diagnóstico de miosite e 15 com ES. O grupo de LES era composto, em sua maioria, de pacientes do gênero feminino (81); tinha idade média de 35,0 $\pm 11,7$ anos, tendo variado de 13 a 62 anos; e o tempo de doença variou de 2 a 384 meses, com média em 78,2 $\pm 76,1$ meses. As características clínicas e laboratoriais, segundo os aspectos avaliados pelo SLEDAI, estão apresentadas nas Tabelas 1 e 2. A avaliação da atividade de doença revelou um escore SLEDAI médio de $11,6 \pm 5,8$ e escores mínimo e máximo de $2 \mathrm{e}$ 30 , respectivamente. Considerando-se arbitrariamente os pacientes em atividade aqueles que apresentavam SLEDAI maior do que 4 , observou-se que 78 pacientes $(95,12 \%)$ apresentavam doença "ativa". O escore médio dos pacientes em atividade foi de 12,12 , tendo variado de 5 a 30 ; e dos pacientes inativos foi de 2,75 , tendo variado de 2 a 4 .

TABELA 1

FREQÜENACIA DE SINAIS E SINTOMAS PRESENTES NA AVALIAÇÃO DOS 82 PACIENTES COM LÚPUS ERITEMATOSO SISTÊMICO CRITÉRIOS AVALIADOS DE ACORDO COM A DEFINIÇÃO DO SLEDAI

\begin{tabular}{lc}
\hline Sinais e sintomas & N (\%) \\
\hline Febre & $24(29,3 \%)$ \\
Alopecia & $70(85,4 \%)$ \\
Rash malar & $46(56,1 \%)$ \\
Lesões de mucosa & $25(30,5 \%)$ \\
Artrite & $44(53,7 \%)$ \\
Pleurite & $3(3,7 \%)$ \\
Pericardite & $1(1,2 \%)$ \\
Glomerulonefrite & $23(28,0 \%)$ \\
Vasculite & $7(8,5 \%)$ \\
Psicose & $1(1,2 \%)$ \\
\hline
\end{tabular}


TABELA 2

FREQÜÊNCIA DAS ALTERAÇÕES LABORATORIAIS PRESENTES NA AVALIAÇÃO DOS 82 PACIENTES COM LÚPUS ERITEMATOSO SISTÊMICO - CRITÉRIOS AVALIADOS DE ACORDO COM A DEFINIÇÃO DO SLEDAI

\begin{tabular}{lc}
\hline Alterações laboratoriais & $\mathrm{N}(\%)$ \\
\hline Leucopenia & $44(53,7 \%)$ \\
\hline Plaquetopenia & $12(14,6 \%)$ \\
\hline Proteinúria & $22(26,8 \%)$ \\
Hematúria & $15(18,3 \%)$ \\
Cilindrúria & $14(17,1 \%)$ \\
Leucocitúria & $6(7,3 \%)$ \\
Anticorpos anti-DNA & $31(37,8 \%)$ \\
\hline Diminuição de C3 & $18(22,0 \%)$ \\
Diminuição de C4 & $30(36,5 \%)$ \\
\hline
\end{tabular}

Para todos os pacientes envolvidos no estudo, foi feita a pesquisa de anticorpos $\mathrm{AN}$, tendo sido encontrada positividade em $48(58,5 \%)$ em LES, dois (14,2\%) dos pacientes com ES e três $(21,4 \%)$ com miosite, correspondendo a uma sensibilidade de 58,5\%, especificidade de $82,14 \%$ e valor preditivo positivo do teste para diagnóstio de LES de $90,56 \%$ nessa população estudada. Uma vez que o cut off desse sistema de ELISA não foi ainda determinado na população brasileira, optamos por analisar os resultados utilizando arbitrariamente um ponto de corte mais alto. Assim, considerando-se o ponto de corte em $40 \mathrm{U}$, encontramos positividade em $44(53,65 \%)$ em LES, um $(6,66 \%)$ dos pacientes com ES e dois (13,33\%) com miosite, correspondendo a uma sensibilidade de $53,65 \%$, especificidade de $90 \%$ e valor preditivo positivo do teste para diagnóstico de LES de 93,61\% nessa população estudada. Adicionalmente, a média dos títulos dos anticorpos $\mathrm{AN}$ foi maior nos pacientes com LES: $86,3 \mathrm{U}$, comparando-se à dos pacientes com ES ou miosite: $45,1 \mathrm{U}(\mathrm{p}<0,05)$. Ainda do ponto de vista de valor diagnóstico, observou-se menor freqüência de positividade de anticorpos anti-DNA do que de anticorpos AN no grupo de LES: 31 (37,8\%).

Buscando a associação entre anticorpos AN e os parâmetros clínicos e laboratoriais avaliados pelo SLEDAI, não encontramos significância com nenhum sintoma ou alteração laboratorial presente, utilizando-se os dois diferentes pontos de corte, exceto para a associação entre febre e presença de $\mathrm{AN}(\mathrm{p}=0,01)$, com o ponto de corte de $20 \mathrm{U}$ (Tabela 3). O título médio dos anticorpos AN foi de 55,83 \pm 45,87 $\mathrm{U}$ nos pacientes ativos e de 25,05 \pm 22,85 U nos inativos. Não houve diferença estatisticamente significativa entre a média dos títulos de AN dos pacientes ativos e inativos $(\mathrm{p}=0,65)$, embora tal análise deva ser interpretada com cuidado, uma vez que a maioria dos pacientes estava no grupo “ativo”. Adicionalmente, não encontramos correlação entre anticorpos AN e anti-DNA nem escore de SLEDAI, embora houvesse uma correlação direta, moderada e estatisticamente significativa entre anti-DNA e escore de SLEDAI nessa mesma população $(\mathrm{r}=0,42 ; \mathrm{p}=0,005)$ (Tabela 4$)$ e $(\mathrm{r}=0,31 ; \mathrm{p}=0,003)$ para um ponto de corte de $40 \mathrm{U}$.

TABELA 3

ANÁLISE DA ASSOCIAÇ̃̃o DA PRESENÇA DE ANTICORPOS ANTINUCLEOSSOMA E DIFERENTES MANIFESTAÇÕES DA DOENÇA NOS 82 PACIENTES COM LÚPUS ERITEMATOSO SISTÊMICO. PONTO DE CORTE PARA EXPRESSAR POSITIVIDADE DE AN DE $20 \mathrm{U}$

\begin{tabular}{lc}
\hline Manifestação & Valor do p (qui-quadrado) \\
\hline Febre & 0,01 \\
\hline Alopecia & 0,61 \\
\hline Aftas & 0,08 \\
\hline Artrite & 0,28 \\
\hline Pleurite & 0,62 \\
\hline Pericardite & 0,41 \\
Vasculite* & 0,31 \\
\hline Psicose & 0,41 \\
\hline Glomerulonefrite** & 0,53 \\
\hline
\end{tabular}

*Vasculite: lesões cutâneas compatíveis com vasculite.

**Glomerulonefrite: presença de proteinúria > 0,5 g/24 horas associada ou não a hematúria, hipertensão arterial e perda de função renal.

TABELA 4

ANÁlise DA CORRELAÇ̃̃O ENTRE OS TÍTULOS DOS ANTICORPOS ANTINUCLEOSSOMA (AN), ANTICORPOS ANTI-DNA E ESCORE DE SLEDAI NOS 78 PACIENTES COM LÚPUS ERITEMATOSO Sistêmico em atividade (Pearson). Ponto de corte para EXPRESSAR POSITIVIDADE DE AN DE $20 \mathrm{U}$

\begin{tabular}{lcc}
\hline & Anti-DNA & SLEDAI \\
\hline AN & $r=0,16$ & $r=0,17$ \\
& $p=0,13$ & $p=0,13$ \\
Anti-DNA & & $r=0,42$ \\
& & $p<0,001$ \\
\hline
\end{tabular}

\section{DISCUSSÃO}

O nucleossoma é a unidade fundamental da cromatina. Durante o processo da apoptose, a cromatina sofre uma clivagem por ação de endonucleases, expondo os nucleossomas, que se comportam como antígenos, sendo capazes de induzir a formação de anticorpos ${ }^{(4,11,12)}$. Sabendo-se que a apoptose 
está aumentada no contexto do LES, espera-se que se identifiquem anticorpos AN nesses pacientes ${ }^{(13)}$. À semelhança do presente estudo, outros trabalhos têm demonstrado a presença de anticorpos AN não só em LES, mas também em outras colagenoses, porém com maior freqüência e com títulos mais altos naqueles com $\mathrm{LES}^{(13)}$. Também à semelhança de nossos resultados, a freqüência de anticorpos AN tem sido maior do que a de anticorpos anti-DNA nas populações de LES estudadas, demonstrando-se a positividade de anticorpos AN em muitos casos em que o anti-DNA é negativo ${ }^{(11,15-18)}$. Por outro lado, Julkunen $e t ~ a l .^{(14)}$ não encontraram maior sensibilidade dos anticorpos AN, comparando-se com os exames tradicionalmente realizados para o diagnóstico de LES.

No presente estudo, optamos por utilizar $20 \mathrm{U}$ como ponto de corte para expressar a positividade dos AN, conforme as recomendações do fornecedor. Porém, tivemos o cuidado de realizar a análise dos dados utilizando também um cut off mais alto, de $40 \mathrm{U}$, uma vez que não é conhecido o comportamento desses anticorpos na população normal brasileira. Curiosamente, os resultados não diferiram significativamente daqueles utilizando um ponto de corte de $20 \mathrm{U}$.

Em vista da dificuldade freqüente no diagnóstico e na identificação de atividade no seguimento desses pacientes, diversos estudos têm buscado novos exames diagnósticos que permitam tal avaliação. Assim, em estudo previamente realizado no nosso serviço, avaliou-se o papel da dosagem

\section{REFERÊNCIAS}

1. Tan EM, Cohen AS, Fries JF, et al.: Special article: the 1982 revised criteria for the classification of systemic lupus erythematosus. Arthritis Rheum 25:1271-7, 1982.

2. Amoura Z, Chabre H, Bach JF, Jacob L: The appearance of antinucleosome antibodies precedes that of anti-double-stranded DNA and anti-histone in murine lupus. Rev Med Interne 14(10):980, 1993.

3. Mohan C, Adams S, Stanik V, Datta SK: Nucleosome: a major immunogen for pathogenic autoantibody-inducing $\mathrm{T}$ cells of lupus. J Exp Med 177(5):1367-81, 1993.

4. Amoura Z, Piette JC, Bach JF, Koutouzov S: The key role of nucleosomes in lupus. Arthritis Rheum 42(5):833-43, 1999.

5. Amoura Z, Koutouzov S, Piette JC: The role of nucleosomes in lupus. Curr Opin Rheumatol 12(5):369-73, 2000.

6. Subcommittee for scleroderma criteria of the American Rheumatism Association Diagnostic and Therapeutic Criteria Committee. Preliminary criteria for the classification of systemic sclerosis (scleroderma). Arthritis Rheum 23(5):581-90, 1980.

7. Bohan A, Peter JB: Polymyositis and dermatomyositis (first of two parts). N Engl J Med 292(7):344-7, 1975.

8. Bohan A, Peter JB: Polymyositis and dermatomyositis (second of two parts). N Engl J Med 292(8):403-7, 1975. sérica da enzima adenosina deaminase como marcador de atividade de doença e concluiu-se que não houve correlação da dosagem dessa enzima e o escore de SLEDAI ${ }^{(19)}$. Alguns trabalhos também têm demonstrado correlação dos anticorpos AN com parâmetros conhecidos de atividade de doença. Desse modo, dois trabalhos estudando anticorpos AN em LES na população brasileira encontraram sua associação com atividade de doença, particularmente renal ${ }^{(20,21)}$. Por outro lado, Quattrocchi et al. ${ }^{(2)}$, estudando anticorpos AN em 47 casos de LES e em 62 pacientes com outras colagenoses, tais como artrite reumatóide, doença mista do tecido conjuntivo, ES e síndrome de Sjögren, além de 22 controles sadios, observaram que, apesar de confirmarem a alta sensibilidade desse teste para LES, não encontraram correlação com atividade de doença em LES, avaliada pelo ECLAM. Tais diferenças podem ser atribuídas a razões metodológicas, particularmente quanto ao instrumento utilizado na avaliação de atividade ou ao método de detecção dos anticopos AN.

Em conclusão, na nossa experiência, embora a pesquisa de anticorpos AN seja um teste de moderada sensibilidade e alta especificidade para o diagnóstico de LES, a nãoassociação com atividade de doença parece não justificar a pesquisa rotineira destes na prática reumatológica.

Declaramos a inexistência de conflitos de interesse.

9. Hawker G, Gabriel S, Bombardier C, Goldsmith C, Caron D, Gladman D: A reliability study of sledai: a disease activity index of systemic lupus erythematosus. Rheumatol 20:657-60, 1993.

10. Crowe W, Kushner I: An immunofluorescent method using Crithidia luciliae to detect antibodies to double-stranded DNA. Arthritis Rheum 20(3):811-4, 1977.

11. Simón JA, Cabiedes E, Ortiz J, Varela A, Guerrero-Sanchéz $\mathrm{J}$ : Anti-nucleosome antibodies in patients with systemic lupus erythematosus of recent onset. Potential utility as a diagnostic tool and disease activity marker. Rheumatology 43:220-4, 2004.

12. Decker P: Nucleosome autoantibodies. Clin Chim Acta 366(1-2): 48-60, 2006.

13. Bruns A, Blass S, Hausdorf G, Burmester GR, Hiepe F: Nucleosomes are major $\mathrm{T}$ and $\mathrm{B}$ cell autoantigens in systemic lupus erythematosus. Arthritis Rheum 44:1320-30, 2000.

14. Julkunen H, Salonen EM, Walle TK, Miettinen A: Antinucleosome antibodies in the diagnosis of systemic lupus erythematosus. Scand J Rheumatol 34(2):122-4, 2005.

15. Min DJ, Kim SJ, Park SH, et al.: Anti-nucleosome antibody: significance in lupus patients lacking anti-double-stranded DNA antibody. Clin Exp Rheumatol 20(1):13-8, 2002. 
16. Saisoong S, Eiam-Ong S, Hanvivatvong O: Correlations between antinucleosome antibodies and anti-double-stranded DNA antibodies, C3, C4, and clinical activity in lupus patients. Clin Exp Rheumatol 24(1):51-8, 2006.

17. Cairns AP, Mcmillan SA, Crockard AD, et al.: Antinucleosome antibodies in the diagnosis of systemic lupus erythematosus. Ann Rheum Dis 62:272-3, 2003.

18. Ghirardello A, Doria A, Zampieri S, et al.: Antinucleosome antibodies in SLE: a two-year follow-up study of 101 patients. J Autoimmun 22:235-40, 2004.

19. Lima I, Néri F, Santiago M: Dosagem sérica de adenosina deaminase em lúpus eritematoso sistêmico: ausência da associação com atividade de doença. Rev Bras Reumatol 45(5):273-9, 2005.
20. Gutiérrez-Adrianzén OA, Koutouzov S, Mota RMS, Medeiros MMDC, Bach JF, Campos HH: Diagnostic value of antinucleosome antibodies in the assessment of disease activity in systemic lupus erythematosus: a prospective study comparing anti-nucleosome with anti-DNA antibodies. Rheumatol 33(8): $1538-44,2006$.

21. Campos LM, Kiss MH, Scheinberg MA, Mangueira CL, Silva CA: Antinucleosome antibodies in patients with juvenile systemic lupus erythematosus. Lupus 15(8):496-500, 2006.

22. Quattrocchi P, Barrile A, Bonanno D, et al.: The role of antinucleosome antibodies in systemic lupus erythematosus. Results of a study of patients with systemic lupus erythematosus and other connective tissue diseases. Reumatismo 57(2):109-13, 2005. 